Kolkova, A. (2020). The Application of Forecasting Sales of Services to Increase Business

Competitiveness. Journal of Competitiveness, 12(2), 90-105. https://doi.org/10.7441/joc.2020.02.06

\title{
THE APPLICATION OF FORECASTING SALES OF SERVICES TO INCREASE BUSINESS COMPETITIVENESS
}

\section{- Andrea Kolkova}

\begin{abstract}
The accurate forecasting of business variables is a key element for a company's competitiveness which is becoming increasing necessary in this globalized and digitalized environment. Companies are responding to this need by intensifying accuracy requirements for forecasting economic variables. The objective of this article is to verify the correctness of the models predicting revenue in the service sector against 6 precision criteria to determine whether the use of certain criteria may lead to the adoption of particular models to improve competitive forecasting. This article seeks to determine the best accuracy predictors in 32 service areas broken down by NACE. Exponential smoothing models, ARIMA models, BATS models and artificial neural network models were selected for the assessment. Six criteria were chosen to measure accuracy using a group of scale-dependent errors and scaled errors. Services for which the result was ambiguous were subject to complete forecasting, both ex-post and ex-ante. Based on the analysis, the main result of the article is that only two types of services do not achieve the same accuracy results when using other measure criteria. It can therefore be said that for $93.75 \%$ of services, an assessment according to one precision parameter would suffice. Thus, a model's competitiveness is not affected by the choice of accuracy.
\end{abstract}

Keywords: forecasting, ETS, ARIMA, BATS, artificial neural network, accuracy, competitiveness JEL Classification: C53, M10, M21, O21

Received: October, 2019

1st Revision: March, 2020

Accepted: March, 2020

\section{INTRODUCTION}

A sustained competitive advantage is the ultimate goal of every company, although opinions on how to achieve this have changed over time. Babikova \& Bucek (2019) report on how since the 1990s the focus on human resources as a factor in the company's success has been increasing. The need for a quantitative assessment of business variables, and in particular future predictions, remains closely linked to business success and its competitiveness. Predicting variables is a fundamental problem of scientific research in the business economy. 
The first attempts to predict economics or business are described in the Bible in Genesis, when Pharaoh predicted economic cycles, which were defined as 7 years of good and 7 years of evil according to a dream in which seven beautiful and fat cows came out of the Nile, followed by seven cows strikingly ugly and thin. In the 20th and 21st centuries, efforts to make the most accurate forecasts have continued, including Brown's model (Brown, 1956) and Holt's model (Holt, 1957), followed by, e.g. (Armstrong, 2001; Bergmaier et al., 2016; Taylor, 2003) and notably (Hyndman \& Athanasopoulos, 2018).

Nowadays, forecasting efforts are focused on a whole range of business variables, with Marček (2016) defining a number of areas the forecasts of business variables applied. Sales forecasts have been addressed in several publications, with retail sales addressed by Alon \& Sadowski (2001), Chu \& Zhang (2003), Pereira et al. (2016), Kolková (2018).

The purpose of this article is to verify the degree of accuracy of service forecasting models based on 6 accuracy criteria, to determine if the use of other criteria can lead to the adoption of another model. This goal will be achieved by the exponential smoothing state space model (hereafter ETS), auto regressive integrated moving average (hereafter ARIMA), BATS and models based on artificial neural networks (hereafter Nnetar).

The hypothesis under review is defined: Using multiple methods of measuring accuracy does not lead to the adoption of different models.

An ex-post forecasting will be carried out for 32 service areas broken down by NACE, focusing on whether another accuracy determination will lead to the adoption of another model. For those services where disproportion occurs, forecasting will be performed both ex-post and exante and the accuracy will be re-evaluated.

\section{THEORETICAL BACKGROUND}

Forecasting can be defined as predicting the future development of a particular quantity based on rational methods and current data (Hyndman \& Athanasopoulos, 2018). Forecasting is of great importance in corporate governance, not only when planning business purchases and processes, but also for strategic management as well as even for risk management in business. A good prognosis is based on a wide range of methods that apply to specific, appropriate conditions. The methods used in this paper are described in Chapter 2.1, with several options for accuracy assessment defined in Chapter 2.2.

\subsection{FORECASTING METHODS}

Forecasting methods can be both qualitative and quantitative; this article deals with quantitative methods only, of which many exist. Choosing the right model is dependent on what data is available and to what extent the data is predictable. The prognostic models also vary according to the time intervals in which they are used as well as many other aspects. Thus highly complex models may be based on artificial intelligence (hereafter AI) as well as simple moving averages. This article will include both simpler ETS models as well as models based on ARIMA, BATS and Nnetar. 
The ETS model is defined by Hyndman et al. (2008) and Bergmaier et al. (2016) with the extended equation relationship of:

$S_{t}=\alpha \sum_{i=0}^{t-1}(1-\alpha)^{i} y_{t-1}+(1-\alpha)^{t} S_{0}$, where

$\mathrm{t}$ is the length of the time series, $\mathrm{y}_{\mathrm{t}-1}$ is a time series value, $\partial$ is an element of $(0,1) \mathrm{s}$ the equalizing constant and $\mathrm{S}_{0}$ is the initial value of smoothing.

ARIMAs assume that values can be compared to a random process (Box et al., 2015). Basically, this can be described as a search for internal data structure and dependencies that generate data with acceptable accuracy (Marček, 2016). The relationship for ARIMA (0, 0, q) can be expressed by:

$S_{t}=\mu+\sum_{j=0}^{q} \varphi_{j} \cdot \varepsilon_{t-1}$, where

$\varphi_{j}$ is regression parameters, $\varepsilon_{\mathrm{t}-1}$ is random errors and $\mu$ is the process mean value.

The BATS model of Delivera et al. (2011) presents a generalization of traditional seasonal models. BATS is an acronym using keywords from the Box-Cox transformation models, ARMA model, trend and seasonal components. This designation must be accompanied by appropriate arguments for defining the Cox-Box parameters and damping the $p$ and $q$ parameters to express the ARMA model parameters, with the seasonal frequency expressed by arguments $m_{1}, m_{2} \ldots \ldots \ldots$ $m_{T}$. Delivera et al. (2011) defines the model according to:

$S_{t}^{(i)}=S_{t-m_{i}}^{(i)}+\gamma_{i} \cdot d_{t}$,

$d_{t}=\sum_{i=1}^{p} \dot{\varphi_{i}} \cdot d_{t-i}+\sum_{i=1}^{q} \theta_{i} \cdot \varepsilon_{t-i}+\varepsilon_{t}$, where

$m_{i}$ denote the seasonal periods, $t, S_{t}(i)$ represents the $i$-th seasonal component at time $t, d t$ denotes $\operatorname{ARMA}(\mathrm{p}, \mathrm{q})$ process and $\varepsilon_{t}$ is a Gaussian white noise process with the zero mean and constant variance.

The principle of an artificial neural network is inspired by the neural network in the human brain. The essence of an artificial neural network is not to find a uniform mathematical function that would simply describe all the effects on a variable (Crone et al., 2011). On the other hand, Nnetar is based on the ability to abstract rules between the input and output values. This is where the targeted weights are adapted, and these algorithms can then be called learning algorithms. Nowadays, neural networks are applied to a wide range of tasks (Marček, 2016).

The forward signal propagation model (Fig. 1) consists of three parts: input signals (synaptic connections), output (axon) and activation function (soma). Based on the assigned weights, individual inputs can be suppressed or favored. The activation function processes information from the input and generates the output. The output then delivers the resulting information to the input of other neurons. 

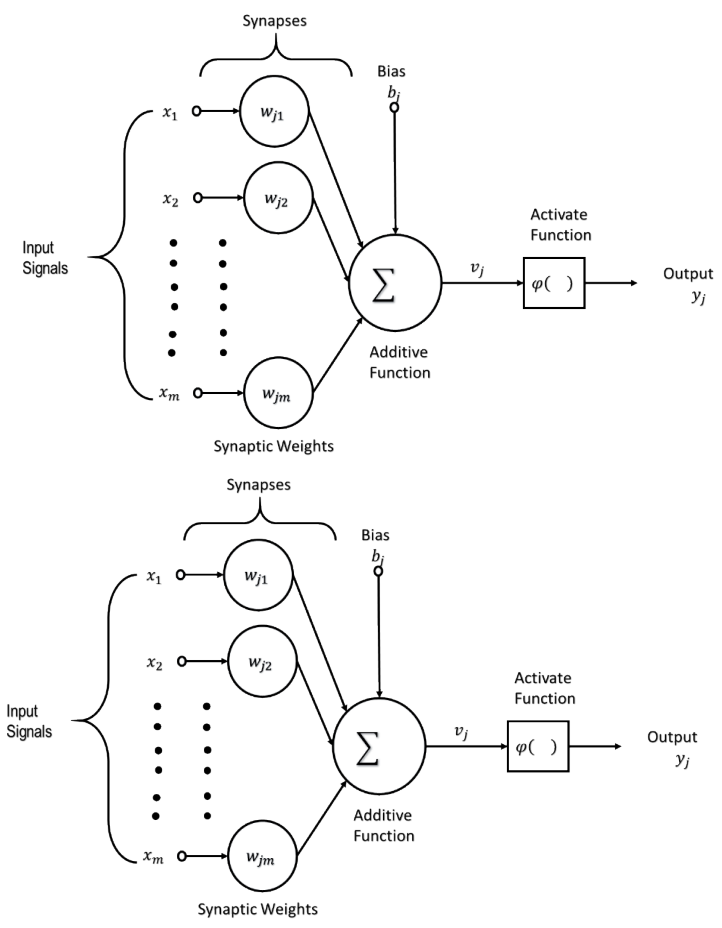

Fig. 1 - Artificial neural network. Source: Hyndman \& Athanasopoulos (2018)

The output of the neuron is calculated when the sum of inputs to the neuron $x_{i}$ multiplied by their specific weights $w_{i}$ exceeds a certain value, which is called a bias neuron. A neuron can be described in this way:

$y_{j}=f\left(\sum_{i=1}^{m} x_{i} \cdot w_{j, i}-b_{j}\right)$, where

$x_{i}$ is a specific value at $i$-th input, $w_{j, i}$ then the weight of this input, $b_{j}$ is the bias, $m$ is the total number of inputs, $f$ is the transformation function and $y$ the output value, all according to the logic in Fig. 1.

\subsection{Forecast Accuracy}

Measurement methods of accuracy can be divided into scale-dependent measures, measures based on percentage errors, scaled errors (Hyndman \& Athanasopoulos, 2018), measures based on relative errors, and relative measures (Hyndman \& Koehler, 2006).

Scale-dependent errors include the mean error (hereafter ME), the mean scaled error (hereafter MSE), the root mean squared error (hereafter RMSE), and the mean absolute error (hereafter MAE). These accuracies are dependent on the scale of the data used and should not be used to compare data sets with different scales. They can be quantified in the following ways: 
$M S E=$ mean $\left(e_{t}^{2}\right)$, where

$e_{t}^{2}$ is a prognosis error, i.e. the difference between the observed value and its forecasting.

RMSE $=\sqrt{ } M S E$

$M A E=\operatorname{mean}\left(\left|\mathrm{e}_{\mathrm{t}}\right|\right)$

$M d A E=\operatorname{median}\left(\left|\mathrm{e}_{\mathrm{t}}\right|\right)$

Percentage errors are already independent on a scale, which can be a great advantage. Their most common use is to compare accuracy across different data sets. Among the most common indicators of this type is the mean absolute percentage error (hereafter MAPE).

$\mathrm{MAPE}=$ mean $\left(\left|\mathrm{p}_{\mathrm{t}}\right|\right)$, where

$p_{t}=100 e_{t} / y_{t}$.

Other possible ones may be:

Median Absolute Percentage Error(hereafter $M d A P E)=$ median $\left(\left|p_{t}\right|\right)$,

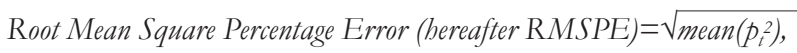

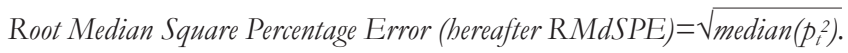

The disadvantage of these models can be that they put a heavier penalty on positive errors than on negative errors. This observation led to the use of the so-called "symmetric",

Symmetric Mean Absolute Percentage Error (sMAPE) $=$ mean $\left(200\left|Y_{t}-F_{t}\right| /\left(Y_{t}+F_{t}\right)\right.$

Symmetric Median Absolute Percentage Error (sMdAPE) $=$ median $\left(200\left|Y_{t}-F_{t}\right| /\left(Y_{t}+F_{t}\right)\right.$

Scaled errors are based on the training MAE. The method that can be included in this group is the mean absolute scaled error (hereafter MASE). These methods were proposed by Hyndman, Koehler (2006) as a general measure of prognosis accuracy.

$M A S E=$ mean $\left(\left|q_{t}\right|\right)$, where

$q_{j}=\frac{e_{j}}{\frac{1}{T-1} \Sigma_{t=2}^{T}\left|y_{t}-y_{t-1}\right|}$.

Measures based on relative errors are alternative types of measurement. It divides each error by using another standard method of forecasting. According to Hyndman \& Koehler (2006), the following parameters can be used:

Mean Relative Absolute Error (hereafter MRAE)=mean $\left(\left|r_{t}\right|\right)$,

Median Relative Abolute Error (hereafter MdRAE) $=$ median $\left(\left|r_{t}\right|\right)$,

Geometric Mean Relative Absolute Error (hereafter GMR AE)=gmean $\left(\left|r_{t}\right|\right)$.

However, in this article, these will not be used. Instead of relative errors, we can use relative measures to get another group of methods. Hyndman \& Koehler (2006) draw attention to the parameter:

RealMAE $=M A E / M A E_{b}$

With this alternative, RMSE, MdAE, MAPE and other methods can also be constructed. Nevertheless, these alternative methods have not been used in the article. 
The most widely used methods by Hyndman \& Athanasopoulos (2018) at present are MAE and RMSE. The MAE method is very easy to understand but leads to prognosis median preferences. In contrast, the RMSE method will lead to the election prognosis method based on the mean value. This is probably the main reason for the widespread use of RMSE today, despite its more difficult interpretability (Hyndman \& Athanasopoulos, 2018).

\section{RESEARCH OBJECTIVE, METHODOLOGY AND DATA}

To create an ex-ante prognosis, it is necessary to split the data into two groups, namely the training data and test data. According to Hyndman \& Athanasopoulos (2018), it is appropriate to make this 80:20 split as shown in Fig. 2.

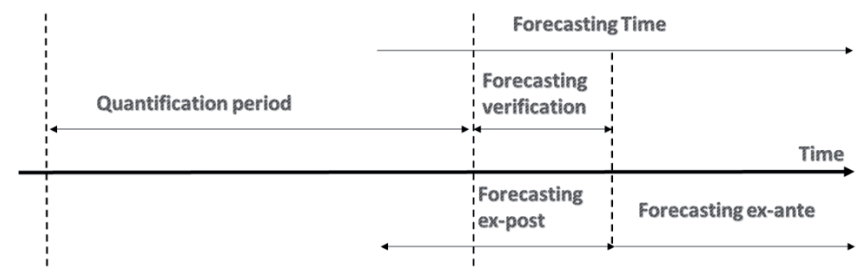

Fig. 2 - Splitting data into the training data and test data. Source: Hyndman \& Athanasopoulos (2018)

The accuracy can be measured using a variety of methods as described in the literature review. In this paper, 6 accuracy measurement methods are used, namely ME, RMSE, MAE, MPE, MAPE, MASE.

The data are taken from the Czech Statistical Office. 32 types of services were considered. For each service, 166 values of monthly sales indices (excl. VAT) in services have been analysed and forecasted since January 2005. As for the Czech Statistical Office, of course, the data taken as non-adjusted data. They are defined in the form of sales indices (excluding VAT), where the average of 2015 is 100 . The Czech economy is traditionally export-oriented, influenced by the German market mainly. It is generally accepted that the Czech Republic benefits from an open EU market, as reported by Polak (2019).

The calculations are performed by the statistical program $\mathrm{R}$ using the packages fpp2, forecast by Hyndman \& Khandakar (2008) and ggplot. The statistical program was used with the help of the graphical interface RKWard in the version modified at VSB - TU Ostrava according to Janurova et al. (2016).

\section{RESULTS}

To verify the suitability of individual accuracy parameters, all these parameters were applied to 32 types of services provided, broken down by NACE. First, it was examined whether the results according to different parameters of accuracy were dissimilar for different parameters. In Chapter 3.1, only two types of services are defined, for which the individual accuracy showed ambigu- 
ous results. Forecasting not only ex-post was applied to these two types of services but also the ex-ante forecasting. The results are summarized in Chapter 3.2. The basic hypothesis of the paper is that the choice of another accuracy criterion does not lead to the choice of another model.

\subsection{Results of forecast accuracy by selected models}

According to the results Nnetar is best suited to be used for forecasting sales revenue. These appear to be the most accurate according to all the assessment criteria selected. An exception is the Food and beverage service activities forecast, where the use of ETS models is most appropriate based on the MPE indicator. Thus, with one exception, which is the hypothesis that using other criteria to assess accuracy does not lead to the adoption of another model.

If we omit artificial neural networks, the results would not be as conclusive as they are. In this case, different models for different types of services would be applied. The results are summarized in Tab. 1.

Tab. 1 - Results of the best model without NNetar. Source: own research

\begin{tabular}{|c|c|c|c|}
\hline \multicolumn{4}{|c|}{ The best model without NNetar } \\
\hline Services & BATS & Information service activities & $\operatorname{ARIMA}(0,1,12)$ \\
\hline $\begin{array}{l}\text { Transportation and } \\
\text { storage }\end{array}$ & $\operatorname{ARIMA}(0,1,12)$ & Real estate activities & ambiguous \\
\hline $\begin{array}{l}\text { Land transport and } \\
\text { transport via pipelines }\end{array}$ & $\operatorname{ARIMA}(1,0,12)$ & $\begin{array}{l}\text { Professional, scientific and } \\
\text { technical activities }\end{array}$ & $\operatorname{ARIMA}(0,0,12)$ \\
\hline Water transport & $\operatorname{ARIMA}(1,1,12)$ & Legal and accounting activities & $\operatorname{ARIMA}(0,0,18)$ \\
\hline Air transport & BATS & $\begin{array}{l}\text { Activities of head offices; } \\
\text { management consultancy } \\
\text { activities }\end{array}$ & $\operatorname{ARIMA}(0,0,12)$ \\
\hline $\begin{array}{l}\text { Warehousing and } \\
\text { support activities for } \\
\text { transportation }\end{array}$ & $\operatorname{ARIMA}(0,1,12)$ & $\begin{array}{l}\text { Architectural and engineering } \\
\text { activities; technical testing and } \\
\text { analysis }\end{array}$ & $\operatorname{ARIMA}(1,0,12)$ \\
\hline $\begin{array}{l}\text { Postal and courier } \\
\text { activities }\end{array}$ & BATS & $\begin{array}{l}\text { Advertising and market } \\
\text { research }\end{array}$ & $\operatorname{ARIMA}(0,0,6)$ \\
\hline $\begin{array}{l}\text { Accommodation and } \\
\text { food service activities }\end{array}$ & $\operatorname{ARIMA}(1,0,12)$ & $\begin{array}{l}\text { Other professional, scientific } \\
\text { and technical activities }\end{array}$ & $\operatorname{ARIMA}(1,1,12)$ \\
\hline Accommodation & $\operatorname{ARIMA}(0,0,12)$ & $\begin{array}{l}\text { Administrative and support } \\
\text { service activities }\end{array}$ & BATS \\
\hline $\begin{array}{l}\text { Food and beverage } \\
\text { service activities }\end{array}$ & ambiguous & Rental and leasing activities & $\operatorname{ARIMA}(1,1,12)$ \\
\hline $\begin{array}{l}\text { Information and com- } \\
\text { munication }\end{array}$ & BATS & Employment activities & $\operatorname{ARIMA}(3,1,12)$ \\
\hline Publishing activities & $\operatorname{ARIMA}(0,0,12)$ & $\begin{array}{l}\text { Travel agency, tour operator } \\
\text { and other reservation service } \\
\text { and related activities }\end{array}$ & BATS \\
\hline
\end{tabular}




\begin{tabular}{|l|l|l|l|}
\hline $\begin{array}{l}\text { Motion picture, video } \\
\text { and television pro- } \\
\text { gramme production, } \\
\text { sound recording and } \\
\text { music publishing activi- } \\
\text { ties }\end{array}$ & ARIMA $(0,1,12)$ & $\begin{array}{l}\text { Security and investigation } \\
\text { activities }\end{array}$ & ARIMA $(0,1,12)$ \\
\hline $\begin{array}{l}\text { Programming and } \\
\text { broadcasting activities }\end{array}$ & ARIMA $(5,0,12)$ & $\begin{array}{l}\text { Services to buildings and } \\
\text { landscape }\end{array}$ & ARIMA $(0,1,12)$ \\
\hline $\begin{array}{l}\text { Telecommunications } \\
\text { ARIMA(0,1,12) }\end{array}$ & $\begin{array}{l}\text { Office administrative, office } \\
\text { support and other business } \\
\text { support activities }\end{array}$ & ARIMA(0,1,12) \\
\hline $\begin{array}{l}\text { Computer program- } \\
\text { ming, consultancy and } \\
\text { related activities }\end{array}$ & ARIMA $(3,0,6)$ & $\begin{array}{l}\text { Other personal service activi- } \\
\text { ties }\end{array}$ & BATS \\
\hline
\end{tabular}

The overall ambiguous results rarely achieve models. If artificial neural networks were included in the models, the only result was the one-time result where the best accuracy was different. If artificial neural networks are excluded, the results are also very similar and an exception is detected only once. The services connected into ambiguous results are summarized in Tab. 2.

Tab. 2 - Results of the best model with and without NNetar. Source: own research

\begin{tabular}{|l|l|l|l|l|l|l|}
\hline & ME & RMSE & MAE & MPE & MAPE & MASE \\
\hline \multirow{2}{*}{$\begin{array}{l}\text { Food and beverage } \\
\text { service activities }\end{array}$} & -0.0056 & 0.6856 & 0.4469 & 0.0099 & 0.4585 & 0.0737 \\
\cline { 2 - 7 } & Nnetar & Nnetar & Nnetar & ETS & Nnetar & Nnetar \\
\hline \multirow{2}{*}{ Real estate activities } & 0.1271 & 9.8630 & 7.0229 & -0.3179 & 6.4335 & 0.3474 \\
\cline { 2 - 7 } & ARIMA* & BATS* & ARIMA* & BATS* & ARIMA* & ARIMA* \\
\cline { 2 - 7 } & NNetar & NNetar & NNetar & NNetar & NNetar & NNetar \\
\hline
\end{tabular}

*the best accuracy model without NNetar

The hypothesis that it is not necessary to subject models to multi-criterion testing is considered to be partially confirmed. For Food and average service activities, it is clear that using the MPE criterion is more appropriate to get the ETS model, all other criteria support the use of the Nnetar model. For Real estate activities, the Nnetar model is the best one, but if we exclude it from the analysis, the results are ambiguous. According to RMSE and MPE, it is best to use the BATS model and other ARIMA criteria.

A total of 32 services were examined and only 2 gave inconclusive results. 30 services confirm the hypothesis that using different methods of measuring accuracy does not lead to the adoption of another model.

\subsection{Complete forecasting of models with ambiguous results}

Food and beverage service activities and Real estate activities were selected for complete forecasting. 
Using the training data, a model was created and forecasting ex-ante was performed on the test data. The training data consisted of a series of 133 data. The data test then contained the remaining 33 values. Forecasting was made for the same length of time as the test data.

First, the Food and beverage service activities forecasting was carried out. In the first step, with help of the ETS models.

The model created had the following parameters:

$$
\operatorname{ETS}(\mathrm{A}, \mathrm{N}, \mathrm{N})
$$

Call: ets $(\mathrm{y}=$ foodServices[1:133])

Smoothing parameters:

alpha $=0.8128$

Initial states:

$1=85.0883$

sigma^2 estimated as 1.672

Obviously, accuracy measurements have been verified here, both for the training set and the test data, with the results shown in Table 3.

Tab. 3 - Results of the ETS models. Source: own research

\begin{tabular}{|l|l|l|l|l|l|l|}
\hline & ME & RMSE & MAE & MPE & MAPE & MASE \\
\hline Training set & 0.03986416 & 7.263571 & 5.440886 & -0.3226107 & 5.873403 & 1.044954 \\
\hline Test set & 1.899488 & 11.63379 & 9.352992 & 1.1158 & 7.524771 & 0.9670299 \\
\hline
\end{tabular}

Forecasting has also been done for the artificial intelligence model. This was created using the training data with the following parameters.

Model: NNAR $(14,8)$

Call: $\operatorname{nnetar}(\mathrm{y}=$ window $($ foodServices, end $=133)$, decay $=0.1)$

Average of 20 networks, each of which is

a 14-8-1 network with 129 weights

options were - linear output units decay $=0.1$

sigma^2 estimated as 1.672

Subsequently, the ex-ante forecasting was made on the test data with the following call:

Call: $\operatorname{nnetar}(\mathrm{y}=$ window $($ foodServices, start $=134)$, model $=$ fit, PI = TRUE $)$

Like ETS, the ex-ante forecasting was justified by accuracy, with the result in Tab. 4.

Tab. 4 - Results of NNetar models. Source: own research

\begin{tabular}{|l|l|l|l|l|l|l|}
\hline & ME & RMSE & MAE & MPE & MAPE & MASE \\
\hline Training set & 0.0021959 & 0.16026 & 0.1202535 & -0.0002688 & 0.1266174 & 0.02309539 \\
\hline Test set & 27.48173 & 28.69967 & 27.48173 & 19.87915 & 19.87915 & 2.841406 \\
\hline
\end{tabular}


Regarding the ex-ante forecasting, it can be seen that on the basis of Nnetar, the results on the training data are definitely better than on the test data. The resulting forecasting is depicted in Fig. 3 .
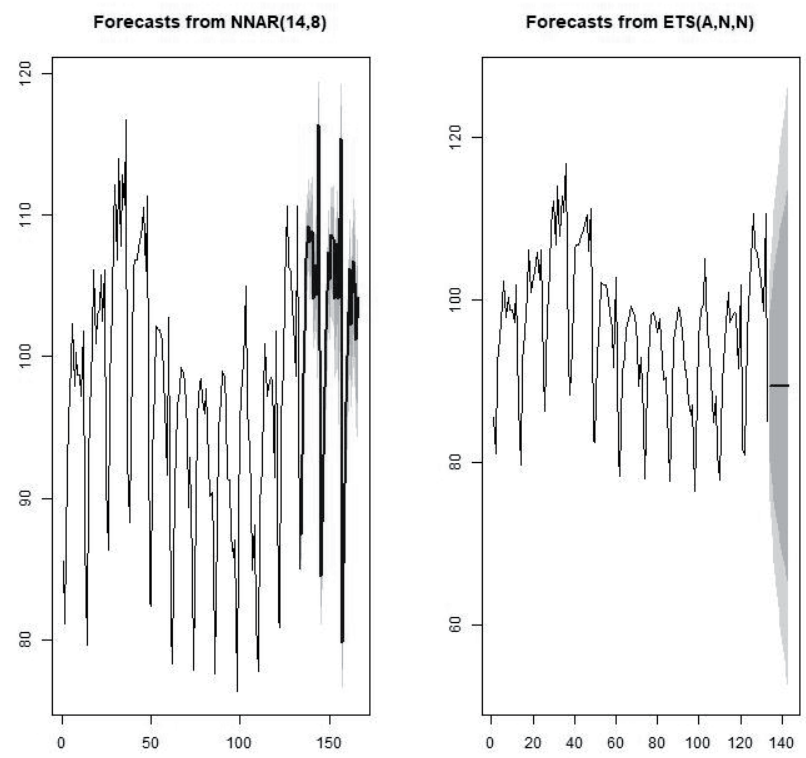

Fig. 3 - Forecast for food and beverage service activities from NNAR $(14,8)$ and ETS $(A, N, N)$. Source: own research

The forecast results can be used to increase a company's competitiveness. Based on this forecast, the forecast demand of the company can be defined. The results show that the demand for these services has been stagnating and will not decrease or increase significantly. The company can use such information to enter a new service or provide a new add-on to an existing service. A stagnating demand could be an impulse to change, thus enabling the company to succeed in a competitive struggle and be a leader in a competitive environment.

Real estate activities were then included in the forecast, which also provided ambiguous results when comparing the model accuracy. As for this variable, both Nnetar and ARIMA and BATS models seemed to be suitable models. Therefore, the three methods mentioned above were forecasted.

Model: $\operatorname{NNAR}(13,7)$

Call: $\operatorname{nnetar}(\mathrm{y}=\operatorname{real}[1: 133], \mathrm{h}=33)$

Average of 20 networks, each of which is

a 13-7-1 network with 106 weights

options were - linear output units

sigma^2 estimated as 0.1388 
Model: ARIMA $(4,1,2)$

Coefficients:

ar1 ar2 ar3 ar4 ma1 ma2

$\begin{array}{llllll}-0.1179 & -0.4984 & -0.4408 & -0.5770 & -0.6798 & 0.5791\end{array}$

$\begin{array}{lllllll}\text { s.e. } & 0.0966 & 0.0735 & 0.0627 & 0.0791 & 0.1011 & 0.1010\end{array}$

sigma^2 estimated as 29.14: $\log$ likelihood $=-408.31$

Model: $\operatorname{BATS}(1,\{5,2\}, 0.895,-)$

Call: bats $(y=\operatorname{real}[1: 133])$

Parameters

Alpha: -0.03006726

Beta: 0.05298213

Damping Parameter: 0.894841

AR coefficients: $0.595094-0.511956-0.053958-0.2406510 .319444$

MA coefficients: -0.5333450 .649805$

Sigma: 5.131929

Again, the accuracy of the training and test data is calculated on these models. The result is given in Table 5 and Table 6.

Tab. 5 - Results of the training data set. Source: own research

\begin{tabular}{|l|l|l|l|l|l|l|}
\hline training set & ME & RMSE & MAE & MPE & MAPE & MASE \\
\hline NNETAR & 0.0014883 & 0.4030958 & 0.2470398 & -0.0059 & 0.2304951 & 0.0406954 \\
\hline ARIMA & 0.04867 & 5.254497 & 4.314075 & -0.1492 & 4.048851 & 0.7106676 \\
\hline BATS & -0.07677 & 5.131929 & 4.2353 & -0.2523 & 3.985058 & 0.6976908 \\
\hline
\end{tabular}

Tab. 6 - Results of the test data set. Source: own research

\begin{tabular}{|l|l|l|l|l|l|l|}
\hline test set & ME & RMSE & MAE & MPE & MAPE & MASE \\
\hline NNETAR & 0.05611 & 5.732733 & 4.80762 & -0.08017 & 4.535749 & 0.8731205 \\
\hline ARIMA & 0.58408 & 4.545122 & 3.670347 & 0.4074042 & 3.519 & 0.6665784 \\
\hline BATS & 0.15467 & 4.567639 & 3.679593 & -0.0251249 & 3.566842 & 0.6682574 \\
\hline
\end{tabular}

The forecasting ex-ante states that in the test data the models based on artificial neural networks show worse accuracy than those based on the training data. The resulting accuracy is better only when the ME coefficient is used. The results of the ex-ante prognosis are more suitable for use with ARIMA models, which show the best rated results based on the most widely used RMSE, MAE, MAPE and MASE. Fig. 4 compares the results of all three models. 
Forecasts from NNAR(13,7)

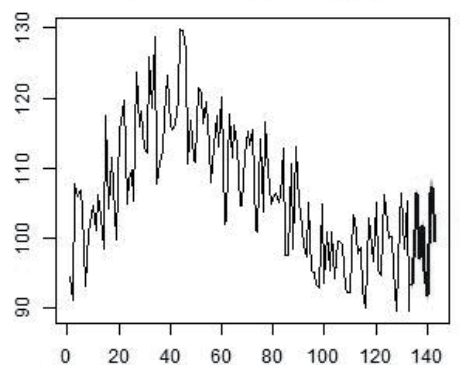

Forecasts from BATS(1, $\{5,2\}, 0.895,-)$

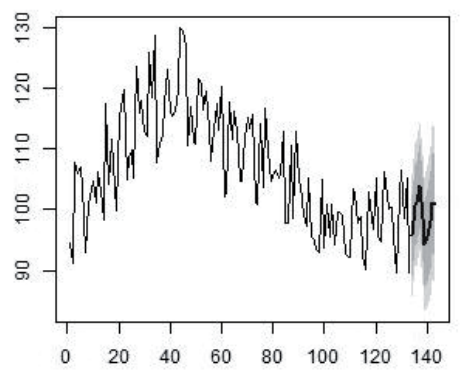

Fig. 4 - Forecast for real estate activities. Source: own research
Forecasts from ARIMA(4,1,2)

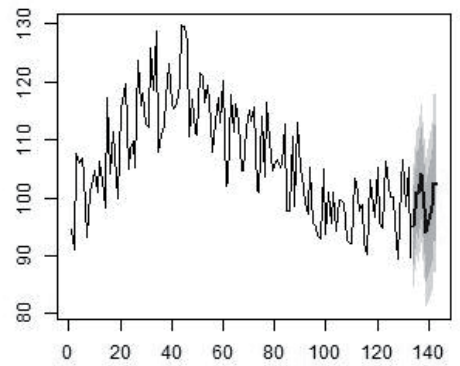

The results of real estate activities again show a service with a stagnating demand. In order for a company to become or remain competitive, it should try to revive the market, which is a good time to innovate or improve the service. However, the forecast also shows that the service has a fluctuating demand, therefore, the appropriate timing of the news is necessary.

\section{DISCUSSION AND CONCLUSIONS}

Several international authors deal with the topic of forecasting as a tool to improve business competitiveness. Semenov et al. (2017) considers quality the most important tool for increasing competitiveness, i.e. product quality forecasting should be a priority of all companies. Forecasting is included as a key element in the researchers' conceptual scheme for increasing competitiveness. Other authors such as Zulfakarova et al. (2016), who have applied their model to the meat processing industry, are also exploring the possibility of increasing their competitiveness with forecasting tools. In accordance with the outputs of this article, they confirm the importance of forecasts for the competitiveness of a company. Many authors have also devoted attention to the use of artificial neural networks as forecasting methods.

Forecasting methods have been analysed several times in a series of competitions in which scientists have examined which of the methods may be most accurate. This series was called the M competitions, with the first one described by Makridakis \& Hibon (1979), although certainly 
more recent competitions are more relevant to this article. The results of M3 were published (Makridakis \& Hibon, 2000) 20 years ago confirming the M3 hypothesis that simple methods overcome more complex ones, as especially the Box-Jenkins method and ARIMA models were much more accurate than others. Regarding results of the most recent event, Makridakis et al. (2018) and Makridakis et al. (2020) identified as the most accurate method for forecasting a hybrid model that combines the advantages of statistical models with models based on artificial intelligence, producing results which is in accordance with those of this article.

In further research it is appropriate to focus on the fact that the results have not been conclusive, i.e. it cannot be said with certainty that the use of artificial neuron networks is the most appropriate in forecasting revenue for services. Green \& Armstrong (2016) have conducted a review of 32 papers, none of which provided clear evidence that more complex methods are more accurate than one-way methods. Zellner et al. (2002) also prefers less computationally demanding models in his concept "Keep It Sophisticatedly Simple." Nevertheless, artificial neural networks offer great scientific potential and should be explored further as well as expanded. Other prognostic models may be included in future research, or other variables that are desirable in the business economy may be used to predict.

The purpose of the paper was to verify the accuracy of models predicting revenue in the service sector based on 6 criteria to determine if the use of certain criteria could lead to the adoption of particular models. It has been hypothesized that the choice of a different accuracy criterion does not lead to the choice of another model. To achieve the goal of the study, accuracy was first calculated for all 32 types of services according to the NACE division. This analysis showed that only two services do not provide a clear result according to all criteria: food and beverage service activities and real estate activities. Although the hypothesis cannot be unambiguously confirmed, it is valid for 30 out of the 32 services analyzed. Thus, it can be said that for $93.75 \%$ of the services, an assessment according to one accuracy parameter would suffice.

The services for which the result was ambiguous were subject to complete forecasting, both ex-post and ex-ante. Based on the initial assessment of accuracy, it can be concluded that, with the exception of food and beverage service activities, the artificial neural network method is the most appropriate method of forecasting for the services sector. However, the results of the exante forecasting are not so clear, i.e. for the test data, the models proved far less accurate than for the training data. Although this is an expected result, the accuracy based on the test data showed in some cases to be even less accurate than that of the models based on ARIMA, BATS and ETS.

Another great challenge is to use predictive models to increase competitiveness. The forecast of two types of services with ambiguous accuracy results showed that both services are in a state of stagnating demand. Such information may be crucial to a potential increase in competitiveness. The opportunity to revive the market with a new service offered, or a new addition to an existing service in a period of stagnation may prove to be a competitive advantage. The ability to create and then maintain a competitive advantage is one of the key factors of a company's competitiveness. A period of stagnating demand should prompt a company to seek new impulses.

Similarly, an increasing demand should signal the company that it is necessary to both continue to satisfy loyal customers as well as reach out to new customers to foster growth. A declining 
demand can inspire a business to create and incorporate new marketing elements to drive demand. Based on the demand forecast through a suitably selected model, the company can choose a suitable competitive strategy.

\section{References}

1. Alon, M. Q., \& Sadowski, R. J. (2001). Forecasting aggregate retail sales: a comparison of artificial neural networks and traditional methods. Journal of Retailing and Consumer Services, 8 (3), 147-156. https://doi.org/10.1016/S0969-6989(00)00011-4

2. Armstrong, J. S. (2001). Principles of forecasting: A bandbook for researchers and practitioners. New York: Kluwer Academic Publishers.

3. Babikova, K., \& Bucek, J. (2019). A Model Replication with an Extension of Students' Perception of Prospective Employer Attractiveness. Journal of Competitiveness, 11 (2), 5-21. https://doi.org/10.7441/joc.2019.02.01

4. Bergmeir, C. H., Hyndman, R. J., \& Benítez, J. M. (2016). Bagging exponential smoothing methods using STL decomposition and Box-Cox transformation. International Journal of Forecasting, 32, 303-312. https://doi.org/10.1016/j.ijforecast.2015.07.002

5. Box, G., Jenkins, G. M., Reinsel, G. C., \& Ljung, G. M. (2015). Time series analysis: forecasting and control, 5th ed. New Jersey: John Wiley \& Sons.

6. Brown, R. G. (1959). Statistical forecasting for inventory control. McGraw/Hill.

7. Crone, S. F., Hibon, M., \& Nikolopoulos, K. (2011). Advances in forecasting with neural networks? Empirical evidence from the NN3 competition on time series prediction. International Journal of Forecasting, 27 (3), 635-660. https://doi.org/10.1016/j. ijforecast.2011.04.001

8. Delivera, A. M., Hyndman, R. J., \& Snyder R. D. (2011). Forecasting time series with complex seasonal patterns using exponential smoothing. Journal of the American statistical association, 106 (496), 1513-1527. https://doi.org/10.1198/jasa.2011.tm09771

9. Green, K. C., \& Armstrong, J. S. (2016). Simple versus complex forecasting: The evidence. Journal of Business Research, 68 (8), 1678-1685. https://doi.org/10.1016/j.jbusres.2015.03.026.

10. Holt, C. E. (1957). Forecasting seasonal and trends by exponentially weighted averages. Pittsburgh: Carnegie Institute of Technology. https://doi.org/10.1016/j.ijforecast.2003.09.015

11. Hyndman, R. J., \& Athanasopoulos, G. (2018). Forecasting: principles and practice, 2nd edition. Melbourne: OTexts. OTexts.com/fpp2

12. Hyndman, R., \& Khandakar, Y. (2008). Automatic time series forecasting: The forecast package for R. Journal of Statistical Software, 27 (3), 1-22. https://doi.org/10.18637/jss.v027.i03

13. Hyndman, R. J., \& Koehler, A. B. (2006). Another look at measures of forecast accuracy. International Journal of Forecasting, 22, 679-688. https://doi.org/10.1016/j.ijforecast.2006.03.001

14. Hyndman, R. J., Koehler, A. B., Ord, J. K., \& Snyder, R. D. (2008). Forecasting with exponential smoothing: The state space approach. Berlin: Springer-Verlag. 
15. Chu, C. W. \& Zhang, G. P. (2003). A comparative study of linear and nonlinear models for aggregate retail sales forecasting. International Journal of Production Economics, 86, 217-231. https://doi.org/10.1016/S0925-5273(03)00068-9

16. Janurová, K., Litschmannová, M., \& Skopal, R. (2016). Supporting freeware for statistical lectures - RKWard. 10th International Days of Statistics and Economics. 711-722. Prague: VŠE, Department of Statistics and Probability, Department of Managerial Economics, Technical University of Košice, Ton Duc Thang University.

17. Kolková, A. (2018). Indicators of Technical Analysis on the Basis of Moving Averages as Prognostic Methods in the Food Industry. Journal of Competitiveness, 10 (4), 102-119. https://doi. org/10.7441/joc.2018.04.07

18. Marček, D. (2016). Supervižvané a nesupervizované učeni z dat: statistický a soft prǐstup. SAEI, 45. Ostrava: VSB - TU Ostrava.

19. Makridakis, S., \& Hibon, M. (1979). Accuracy of forecasting: an empirical investigation (with discussion). Journal of the Royala Statistical Society, 142, 97-145.

20. Makridakis, S., \& Hibon, G. (2000). The M3-competition: results, conclusions and implications. International Journal of Forecasting, 16 (4), 451-476. https://doi.org/10.1016/S01692070(00)00057-1

21. Makridakis, S., Spiliotis, E., \& Assimakopoulos, V. (2018). The M4 Competition: Results, findings, conclusion and way forward. International Journal of Forecasting, 34, 802-808. https:// doi.org/10.1016/j.ijforecast.2018.06.001

22. Makridakis, S., Spiliotis, E., \& Assimakopoulos, V. (2020). The M4 Competition: 100,000 time series and 61 forecasting methods. International Journal of Forecasting, 36, 54-74. https://doi. $\operatorname{org} / 10.1016 /$ j.ijforecast.2019.04.014

23. Pereira Da Veiga, C., Pereira Da Veiga, C. R., Puchalski, W., Coelho, L. S., \& Tortato, U. (2016). Demand forecasting based on natural computing approaches applied to the foodstuff retail segment. Journal of Retailing and Consumer Services, 2016 (31), 174-181. https://doi. org/0.1016/j.jretconser.2016.03.008

24. Polak, J. (2019). Determining Probabilities for a Commercial Risk Model of Czech Exports to China with Respect to Cultural Differences and in Financial Management. Journal of Competitiveness, 11 (3), 109-127. https://doi.org/10.7441/joc.2019.03.07

25. Semenov, V. L., Zakharova, A. N., Chaynikov, V. N., Patianova, A. O., \& Dulina, G. S. (2017). Elaboration of conceptual framework of providing competitiveness of production with use of forecasting techniques. International Conference on Trends of Technologies and Innovations in Economic and Social Studies 2017. https://doi.org/10.2991/ttiess-17.2017.99

26. Taylor, J. W. (2003): Exponential smoothing with a damped multiplicative trend. International Journal of Forecasting, 19, 715-725. https://doi.org/10.1016/S0169-2070(03)00003-7

27. Zellner, H. A, Keuzenkamp, M., \& Mcaleer, (2002). Simplicity, Inference and Modelling: Keeping it Sophisticatedly Simple. Cambridge: Cambridge University Press. https://doi.org/10.1017/ CBO9780511493164 
28. Zulfakarova, L. F., Kundakchyan Rezeda, M., Vakhitova, T. M., \& Gadelshina Landysh A. (2016). Profit Forecast as a Tool to Improve Enterprises Competitiveness. Academy of Strategic Management Journal, 15, 89-95.

\section{Contact information}

Ing. Andrea Kolkova, Ph.D.

VSB - Technical University of Ostrava, Faculty of Economics

Department of Business Administration

Czech Republic

E-mail: andrea.kolkova@vsb.cz.

ORCID: 0000-0002-4764-3164 